\section{LA CONSTITUCIÓN DE WEIMAR Y LOS DERECHOS SOCIALES \\ La influencia en el contexto constitucional y legal colombiano a la luz de los derechos sociales asistenciales a la seguridad social en salud}

\section{José O. López Oliva*}

Fecha de recepción: 9 de Noviembre de 2010

Fecha de aceptación: 30 de Noviembre de 2010

Artículo Resultado de Revisión.

\section{Resumen}

La Constitución de de la República de Weimar expedida en 1919, se erige como la primera constitución en el mundo que hace alusión a disposiciones relacionadas con los derechos sociales asistencias, concretamente a la seguridad social en salud; estas normas fueron impulsadas por la socialdemocracia alemana que propendía por la protección a los citados derechos. En Colombia, fue el constituyente de 1936 quien acogió los planteamientos normativos que estaban imperando en Alemania, encaminados a la protección derechos sociales

* Docente investigador TC Universidad Militar Nueva Granada. Abogado Candidato a Magister en Derecho con enfoque en Derecho de la Responsabilidad y Seguros de la Universidad de los Andes, Magister de la Universidad Carlos III de Madrid (España), Especializado en Derecho Comercial de la Universidad Pontificia Bolivariana de Medellín; con estudios de postgrado en Derecho Penal y Probatorio de la Universidad del Rosario. Consultor y conferencista a nivel nacional e internacional, profesor Universitario de Pregrado y Postgrado, Catedrático a nivel nacional dentro del programa de capacitación a verificadores de las condiciones de habilitación de prestadores de servicios de salud coordinado por el Ministerio de Protección Social. Docente certificado a nivel internacional por la Life Office Management Asociation, Inc - Loma con sede en Atlanta-Georgia (USA). Ha escrito y publicado varios textos de contenido jurídico. Línea de investigación grupo Derecho Público, Facultad de Derecho, UMNG. jose. lopez@unimilitar.edu.co; joselopezoliva@hotmail. com asistenciales sanitarios, consagrados en derechos y no como caridad.

\section{Palabras clave}

Constitución de Weimar, derechos sociales, derechos asistenciales, salud, caridad.

\section{THE WEIMAR CONSTITUTION AND THE SOCIAL RIGHTS \\ The influence in the context constitutional and legal Colombian in the light of the social rights care to social security in health}

\begin{abstract}
The Constitution of the Weimar Republic issued in 1919, it stands as the first constitution in the world that alludes to provisions related to the social rights attendances, specifically to the health and social security; these rules were driven by the social german which he by the protection of such rights. In Colombia, was the constituent of 1936 who welcomed regulatory approaches than were prevalent in Germany, aimed at protecting social rights health care, enshrined in rights and not as charity.
\end{abstract}

\section{Key words}

Weimar constitution, social rights, welfare, health, charity.

\section{INTRODUCCIÓN}

El presente escrito, es resultado de un trabajo exploratorio donde se analiza, sistematiza e integra el resultado de una investigación bibliográfica relacionada con la influencia en el contexto constitucional y legal colombiano, de la Constitución alemana de Weimar donde se consagran por primera vez los derechos sociales asistenciales como la salud.

E1 11 de noviembre de 1919 se expide en Alemania la Constitución de Weimar, por medio de la cual se presentan grandes disposiciones entre 
las que se cuentan las siguientes: se erige este país como una república federal, estableciendo que el presidente será elegido por votación popular; dicho mandatario al momento de formar el gobierno contará con la facultad de elegir un canciller, así como revisará y vetará las leyes expedidas por el legislativo y controlará los desmanes provocados por los ciudadanos de la época, inclusive mediante la declaratoria de estados de excepción sin límites.

Asimismo, La Constitución de Weimar ${ }^{1}$ dio origen al denominado constitucionalismo social $^{2}$ que consagra los principios de los derechos sociales asistenciales de la seguridad social en salud, cuyas disposiciones se centran en la protección de los menos favorecidos.

Las repercusiones de la Constitución de Weimar en Colombia son relevantes, por cuanto esta es la primera carta magna en el mundo que hace referencia a disposiciones de

\footnotetext{
La Constitución de Weimar al igual que la Constitución de México la cual fue sancionada en el año de 1917, fue la promotora del Constitucionalismo Social. La constitución de Weimar también fue denominada como Constitución Social. Es importante indicar que en el año de 1919, fue creada la Organización Internacional del Trabajo, donde tuvieron gran protagonismo los sindicatos, quienes fueron las voces de los trabajadores que reclamaban la implementación de los derechos sociales asistenciales como la salud. Véase: VANOSSI, Jorge Reinaldo. El Estado de Derecho en el Constitucionalismo Social. Editorial EUDEB. Buenos Aires. 1994. Véase igualmente: TIRADO MEJÍA, Alvaro, et al. Reforma Constitucional de 1936. Colección Pensadores Políticos Colombianos. Cámara de Representantes de Colombia. Bogotá. 1986

2 La Constitución de Weimar fue la de mayor influencia en Europa y América, por su filosofía de índole social en las comunidades industriales, que no contaban con derechos asistenciales como la salud. El constitucionalismo social se caracteriza por el reconocimiento de los derechos sociales como la asociación, la salud, la huelga, y se basa en principios como la equidad, surgiendo de esta manera la seguridad social, como muestra en salud y los derechos laborales (salario, descanso obligatorio entre otros). Asimismo, surgen los derechos sociales asistenciales patrocinados por el Estado en los campos de la salud, vivienda y educación. Ibidem.
}

orden social, lo que influyó en las reformas constitucionales colombianas verbigracia la de 1936, y las legales que se indicarán más adelante; estas cláusulas sociales, se adecuaron a las cartas constitucionales nacionales con el fin de consagrar los derechos y garantías propios de las normas sociales, por ejemplo el de la seguridad social en salud.

En consecuencia, lo que se pretende demostrar en el presente escrito, es la influencia que tuvo la Constitución weimariana de 1919, en las consagraciones constitucionales y legales colombianas alrededor de los derechos sociales $^{3}$ como la seguridad social en salud.

Para tal fin, en primer lugar, (1) se hace un breve análisis del marco histórico antecedente a la Constitución de Weimar, donde se presentaron varios hechos que orientaron la protección de los derechos sociales asistenciales, hasta llegar a la expedición de dicha carta donde estos se consagran; en segundo lugar, (2) se analiza la influencia que tuvo la mencionada Constitución, en algunas reformas constitucionales colombianas como la de 1936 y legales en lo referente a la implementación de los derechos sociales asistenciales y de la seguridad social en salud; (3) finalmente, se presentan unas breves conclusiones.

\section{LA CONSTITUCIÓN DE WEIMAR DE 1919 Y LOS DERECHOS SOCIALES ASISTENCIALES COMO LA SEGURIDAD SOCIAL EN SALUD EN COLOMBIA}

En principio, es importante indicar que los derechos sociales asistenciales en Alemania, incluido el de seguridad social, han incidido en la estructura de los modernos sistemas de seguridad

AGUILO REGLA, Joseph. La Constitución como fuente de derecho. Ponencia en el X seminario internacional de Teoría y Filosofía del Derecho. Universidad Nacional de Colombia. Bogotá. 2002. Disponible en: http:// www.cervantesvirtual.com/servlet/SirveObras. u.v. 09/11/09 
social ${ }^{4}$ como el colombiano. Dicho modelo, tal como lo indica el profesor francés Paul Durand ${ }^{5}$, es consecuencia del crecimiento demográfico y el proceso de industrialización presentado en Alemania a mediados del siglo XIX.

Esto, es resultado del resurgimiento del proletariado urbano ${ }^{6}$ y una nueva clase social formada por obreros industriales los cuales carecían de seguridad social ${ }^{7}$, y estaban particularmente expuestos a los riesgos sociales ${ }^{8}$ que afectaban su salud.

Así, la aparición en Alemania del aludido proletariado, trajo como resultado la llegada de asociaciones sindicales y el advenimiento del partido social demócrata, que propendía por la protección de los derechos sociales de los trabajadores.

De hecho, se empieza a legislar como lo enseña el profesor Gerardo Arenas Monsalve, en torno a la "obligación de los empleadores de asegurar prestaciones de enfermedad a sus dependientes y sobre las responsabilidades del empleador en los accidentes de trabajo" . Lo anterior, condujo a la creación de las denominadas "cajas de enfermedad"10.

4 ARENAS MONSALVE, Gerardo. El derecho colombiano de la seguridad social. Legis Editores S.A. Bogotá. 2009. p. 21.

5 DURAND, Paul. La politica contemporánea de seguridad social. Ministerio de Trabajo y Seguridad Social. Madrid. 1991. p. 102 -148.

6 ARENAS MONSALVE, Gerardo. El derecho colombiano de la seguridad social. Op. cit. p. 21.

7 Los salarios que cobraban estos trabajadores eran pírricos, sumado a las extensas jornadas laborales y la ausencia de algún tipo de seguridad social.

8 ARENAS MONSALVE, Gerardo. El derecho colombiano de la seguridad social. Op. cit. p. 21. Los riesgos sociales están relacionados con los factores, como el laboral, que repercuten en la salud de las personas.

9 Idem. p. 22.

10 Las cajas de enfermedad, que hasta la fecha operan en Alemania y en otros países como Colombia, es un seguro que en aquella época se manejaba como un "fondo" que cubre los riesgos en salud.
Dentro del modelo ${ }^{11}$ de protección de los derechos sociales como el seguro social, los empleadores junto con los trabajadores y el Estado -al que se le empiezan a imponer responsabilidades públicas-, eran solidariamente responsables de la operatividad del mencionado modelo. Según lo señala la profesora Natalia Paredes Hernández, el modelo de seguridad social a finales del siglo XIX fue parte de la construcción de la república germano-prusiana, que formaba estados autónomos con el fin de incluir en esta república, al proletariado industrial emergente ${ }^{12}$.

Ya en la Alemania de 1881, se busca promover el bienestar no solo individual sino también colectivo, que algunos denominaron "bienestar social", categoría que se empieza a implementar con el mensaje del emperador alemán Guillermo I dirigido al Reichstag o parlamento de aquella época, cuando el 17 de noviembre de 1881, anuncia un "programa de política del trabajo con una nueva visión del Estado" ${ }^{13}$; este, centrado como se señaló, en el bienestar colectivo preferentemente de los más necesitados, naciendo de esta manera el régimen de los seguros sociales obligatorios ${ }^{14}$.

Por su parte, el 15 de mayo de 1891 el papa León XIII, mediante su encíclica Renum Novarum, en defensa de los intereses de los asalariados promueve la organización de los seguros sociales los cuales, según el profesor Jesús María Rengifo $^{15}$, arrojan buenos resultados en Alemania.

11 En esta época (mediados del siglo XIX) no se puede hablar de "Sistema" como el actual de Seguridad Social en Salud, sino únicamente de modelo sin parámetros estructurales claros.

12 PAREDES HERNÁNDEZ, Natalia. Derecho a la salud, su situación en Colombia. Ediciones Antropos Ltda.. Bogotá. 2003. p. 15.

13 RENGIFO O, Jesús María. La Seguridad Social en Colombia. Editorial Temis S.A. Bogotá. 1989. p. 30 y ss.

14 Ibidem. Los cuales operan en la actualidad en Colombia y que son una clara influencia de la normatividad alemana.

15 Ibídem. 
Posteriormente, varias naciones siguen este ejemplo como la colombiana en $1948^{16}$, que se instaura sobre las mismas bases alemanas mediante instituciones similares como la citada organización social asistencial.

Resultado de los episodios anteriores, se expiden en Alemania las leyes que organizan los seguros de enfermedad ${ }^{17}$, accidentes de trabajo y de invalidez y vejez con la característica de la obligatoriedad, que todavía opera en estos días en países como Colombia, esto es, que tanto los empleadores, como los trabajadores y el Estado deben hacer los aportes o pagar las cuotas correspondientes y así afiliarse al "sistema"18.

Posteriormente, a comienzos del siglo XX se originaron movimientos sociales que promovieron la consagración de derechos de rango social centrados en la salud, los cuales se plasmaron por primera vez en la Constitución alemana de Weimar de 1919.

Los derechos sociales asistenciales de salud que protegían preferencialmente a los menos favorecidos y a los trabajadores en ese momento histórico (1919), surgieron según Juan Carlos Abreu, producto de la idea socialdemócrata según la cual "el desarrollo integral del ser humano reclama que la comunidad organizada y el Estado, actúen positivamente a fin de crear, mediante esa acción, las condiciones necesarias para el goce eficaz de estos derechos" 19 .

$16 \quad$ Ibídem. Luego en el año de 1971 y 1977 respectivamente. En 1948 se crea el Seguro Social con base en la experiencia alemana.

17 Las leyes del 15 de junio de 1883 (seguros de enfermedad), del 6 de julio de 1884 (accidentes de trabajo) y del 22 de junio de 1889 (seguro de invalidezvejez). Véase: ARENAS MONSALVE, Gerardo. El derecho colombiano de la seguridad social. Op. cit. p. 21.

18 RENGIFO O, Jesús María. La Seguridad Social en Colombia. Op. cit. p. 65. El concepto "sistema" hay que tomarlo ya en la actualidad, pero en Alemania todavía finalizando el siglo XIX hay que concebirlo como "modelo" porque no existía una estructura clara de la seguridad social.

19 ABREU Y ABREU, Juan Carlos. Derechos Humanos, intereses difusos y medio ambiente: un problema jurídico
Por consiguiente, la Constitución de Weimar, también llamada constitución social, es el resultado de la expresión ideológica de la socialdemocracia alemana, que se instauró mediante el partido mayoritario en la Asamblea Constituyente elegida el 19 de enero de $1919^{20}$.

Esta constitución, aparece con posterioridad a la primera guerra mundial que tuvo lugar entre 1914 y 1918, cuya confrontación trajo como consecuencia una profunda recesión económica que afectó a los ciudadanos de Europa, entre ellos a los alemanes; estos con la nueva constitución, por primera vez cuentan con 57 artículos relacionados con los derechos fundamentales que deben ser protegidos por el Estado, así como disposiciones referidas a los derechos sociales, aunque a un nivel muy general y abstracto, entre los que se incluye el de la asistencia pública en salud ${ }^{21}$.

Todo, dentro del desarrollo e implementación del denominado constitucionalismo social, cuya ideología hace que se consoliden los derechos sociales y entre ellos la seguridad social y los derechos asistenciales prestacionales a cargo del Estado ${ }^{22}$ verbigracia la salud.

Justamente, así lo indican los profesores Álvaro Tirado Mejía y Magdala Velásquez Toro, al señalar que mientras "los partidos burgueses obtenían el reconocimiento de la libre empresa, la garantía de la herencia y de la propiedad; los

insoslayable. VI Congreso Iberoamericano de Academias de Derecho. Academia Mexicana de Jurisprudencia y Legislación. 2009. Disponible en: www.acj.org u.v. 24/11/2009

20 TIRADO MEJÍA, Alvaro, et al. Reforma Constitucional de 1936. Op. cit. p. 29.

21 Véase las interesantes reflexiones que hace sobre este tema el profesor BERNAL PULIDO, Carlos. En: Fundamento, concepto y estructura de los derechos sociales, una crítica a ¿Existen derechos sociales? De Fernando Atria. Universidad Externado de Colombia. Bogotá. 2002. p. 21

22 BERNAL PULIDO, Carlos. Fundamento, concepto $y$ estructura de los derechos sociales, una critica a ¿Existen derechos sociales? Op. Cit. p. 42. 
socialdemócratas, la protección de la fuerza de trabajo, la libertad de coalición, y la obligación para el Estado de crear un sistema ${ }^{23}$ general de seguridad social con estructuras democráticas" ${ }^{24}$. (Negrillas fuera del texto)

Dicha obligación estatal, fue el punto de partida para la creación de un "Sistema" (ya no modelo) General de Seguridad Social, dentro de la consagración de los derechos sociales que paulatinamente se fueron estableciendo con posterioridad, gracias a la Constitución weimariana de 1919.

De esta manera, tanto los preceptos sociales weimarianos de rango constitucional y las disposiciones legales alemanas, se despliegan con el objeto de proteger progresivamente a la población alemana ${ }^{25}$, lo cual es tomado como referencia, en el caso colombiano, por los constituyentes de 1936 y los legisladores de este período.

El 11 de noviembre de 1919 fue entonces la fecha de la sanción de la Constitución Alemana de Weimar, erigiéndose como la primera carta constitucional en el mundo que hace referencia a cláusulas sociales, como los derechos asistenciales en salud señalados con anterioridad.

De otro lado, y a manera de ilustración, hay que indicar que con la nueva constitución, Alemania se instituye como una república federal que cuenta con nueve estados; se dispone, de la misma forma, que el presidente sea elegido por votación popular, y se le envisten de extraordinarias facultades inclusive para restringir las libertades individuales y decretar estados de

23 Aquí se empieza a consagrar el concepto de "Sistema" y no de "modelo".

24 TIRADO MEJÍA, Alvaro, et al. Reforma Constitucional de 1936. Op. cit. p. 29 y ss.

25 Se trata de proteger a los trabajadores, a las personas menos favorecidas y se "crea una nueva forma de seguro social a través del seguro a supervivientes del trabajador que fallece". Ibíd. p. 24. excepción sin censura alguna ${ }^{26}$, aspecto que será corregido en la ley fundamental alemana, por cuanto en esta priman dichas libertades.

En suma, las normas indicadas en la Constitución de Weimar, influyeron tanto en la consagración de disposiciones constitucionales colombianas como en las de otras naciones, las que se inclinaron por medio de sus cartas magnas, a garantizar los principios propios de los derechos sociales asistenciales en seguridad social en salud, dirigiendo la reorganización estatal a la observancia de aquellos.

Influencia de la Constitución de Weimar en las disposiciones constitucionales y legales colombianas en torno a los derechos sociales asistenciales en salud

Las constituciones colombianas del siglo XIX no trataron aspectos relacionados con los derechos sociales y la asistencia pública en salud, como si lo hizo la constitución weimariana de 1919 así haya sido de manera abstracta; y mucho menos se trató en Colombia el tema de la estructura de un sistema de seguridad social.

En la constitución colombiana expedida en el año de 1886, se hace una breve alusión a los "deberes" del Estado, lo cual se asocia con la "caridad" más no con el "derecho" que les asiste a los ciudadanos, de contar con la aplicación de derechos sociales asistenciales sanitarios.

La citada constitución indica en uno de sus apartes, que las autoridades están instituidas para "asegurar el cumplimiento de los deberes sociales del Estado y de los particulares" 27. Se evidencia entonces que la noción de "deber" en la Constitución de 1886, señalada anteriormente, sea asocia con la de "caridad" excluyendo la mención de "derecho", en este caso a la asistencia en salud.

26 PÉREZ VILLA, Jorge. Compendio de Derecho Constitucional. Editorial Leyer. Bogotá. 1998. p. 303.

27 PAREDES HERNÁNDEZ, Natalia. Derecho a la salud, su situación en Colombia. Op. cit. p. 43. 
Paulatinamente, en Colombia entre los años de 1910 y 1936 se supera la categoría de "caridad" de la asistencia en salud por ejemplo, sustituyéndola por la de "obligación" a cargo del Estado acreedor de los ciudadanos en relación con esta asistencia pública; ello se fomenta con las ideas sociales que predominan en Alemania a principio del siglo XIX, y que son recogidas por el general Uribe Uribe ${ }^{28}$.

Este militar y abogado antioqueño presenta lo que él denomina "proyecto de socialismo de Estado" en el que propone organizar la asistencia pública, no desde el punto de vista de la "caridad" sino como "derecho"; a esta propuesta, el ideólogo de izquierda y también antioqueño Gerardo Molina, asintió señalando peyorativamente que a los "indigentes les parece mejor no recibir como limosna lo que consideran que se les debe por derecho" 29 .

Aquello, según lo indica Arenas Monsalve, es una de las conquistas importantes del pensamiento jurídico en los últimos tiempos, consagradas bajo el principio señalado con anterioridad, de que "frente del Estado el hombre es un acreedor" 30 de derechos y no de "caridad;" nociones recogidas de la filosofía socialdemócrata alemana.

No obstante, en Colombia hasta el año de 1928 no existía un derrotero claro alrededor de la protección de los derechos sociales asistenciales en salud; naturalmente, el gobierno deseaba ordenar la escasa legislación existente, y para ello se tuvo en cuenta todo lo tocante a la consagración de los derechos asistenciales, con la aparición de los seguros sociales en Alemania ${ }^{31}$.

28 ARENAS MONSALVE, Gerardo. El derecho colombiano de la seguridad social. Op. cit. p. 64

29 MOLINA, Gerardo. Las ideas liberales en Colombia. Tomo I. 1848-1914. $8^{\text {a }}$ edición. Ediciones Tercer Mundo. Bogotá. p. 256.

30 Ibídem.

31 RENGIFO O, Jesús María. La Seguridad Social en Colombia. Op. cit. p. 44.
En este orden de ideas, si bien es cierto el Estado colombiano empieza a ser protagonista alrededor de los derechos sociales asistenciales de la salud, es desde comienzos del siglo XIX donde se empiezan a consagrar estos derechos en la constitución colombiana de 1936, aunque de manera abstracta $^{32}$ igual que en Alemania. El constituyente colombiano del 36, tomó en cuenta los principios de la Constitución weimariana de 1919, la cual consagró por primera vez los derechos sociales.

Así se revela en el artículo 19 de la reforma constitucional colombiana del 36 al señalar que:

"la asistencia pública es función del Estado. Se deberá prestar a quienes careciendo de medios de subsistencia y de derecho para exigirla a otras personas, que estén fisicamente incapacitados para trabajar. La ley determinará la forma como se preste la asistencia y los casos en que deba darla directamente el Estado ${ }^{\text {"33 }}$ (Negrillas fuera del texto).

Asimismo, en el gobierno del presidente tolimense Alfonso López Pumarejo, en el cual se llevó a cabo la enmienda constitucional expuesta, y que según los profesores Tirado Mejía y Velásquez Toro ${ }^{34}$, es uno de los mandatarios más importantes de la historia de Colombia, se presentaron transformaciones relevantes; lo anterior, porque mediante la reforma constitucional de 1936 el país acogió

32 Hay que aclarar que la protección de los derechos sociales visto como el conjunto de las medidas institucionales de satisfacción de necesidades en salud por ejemplo, se consagró en la ley americana de seguridad social de 1935, influenciada también por la carta weimariana de 1919, "pero encontró su expresión más completa en Gran Bretaña, con el informe "Beveridge", cuya influencia produjo un movimiento internacional favorable a su implantación, que se tradujo posteriormente en las legislaciones nacionales". Véase: ARENAS MONSALVE, Gerardo. El derecho colombiano de la seguridad social. Op. cit. p. 64

33 CONSTITUCIÓN NACIONAL DE COLOMBIA DE 1936. Art. 19.

34 TIRADO MEJÍA, Alvaro, et al. Reforma Constitucional de 1936. Op. cit. p. 3. 
los nuevos ordenamientos que se estaban presentando en Europa y particularmente en Alemania, orientados a la protección de los derechos sociales asistenciales como la salud.

Colombia no era ajena a las profundas transformaciones en la economía y la sociedad de ese momento, las cuales le afectaban al igual que a Alemania, país que se encontraba convulsionado por la crisis del capitalismo desde $1929^{35}$.

Así las cosas, según lo señala el profesor Jacobo Pérez Escobar, fue a partir del Acto Legislativo No. 1 mediante el cual se reforma la Constitución de Colombia del 36 "cuando nuestro sistema político sufrió un ligero viraje ideológico hacia el socialismo en una modalidad que aún subsiste" 36 y cuyas bases son tomadas de los partidos de izquierda alemanes ${ }^{37}$.

Dentro de la enmienda presentada en el 36, se plasmaron reformas que según lo indica el profesor Tulio Enrique Tascón, fueron tomadas de la Constitución Alemana de Weimar de 1919, con disposiciones relacionadas con el derecho social asistencial público en salud por ejemplo, a cargo del Estado ${ }^{38}$.

La reforma mencionada, en suma, enuncia las consecuencias inevitables de las valiosas transformaciones sociales presentadas con posterioridad a la primera guerra mundial; hechos que repercutieron en Alemania en la estructuración de las normas encaminadas a la protección de los derechos sociales, y que los

$35 \quad$ Ibidem.

36 PÉREZ ESCOBAR, Jacobo. Derecho Constitucional Colombiano. Editorial Temis S.A. Bogotá. 1997. p. 200.

37 Comolos socialdemócratas y la izquierda democrática, por ejemplo.

38 TASCÓN, Tulio Enrique. Historia del Derecho Constitucional Colombiano. Universidad Externado de Colombia. Bogotá. 2005. p. 269. Asimismo, en la reforma constitucional de 1936 influenciada por la Constitución de Weimar, se consagró que "el trabajo era una obligación social y gozaría de la especial protección del Estado; que se garantizaba el derecho de huelga, salvo en los servicios públicos, y que las leyes podrían establecer el patrimonio familiar inalienable e inembargable". Ibídem. constituyentes del 36 tuvieron en cuenta en la estructura de la carta magna colombiana ${ }^{39}$.

Al estudiar la Gaceta que contiene las discusiones referidas a la enmienda constitucional de 1936, se muestra la tendencia de los constituyentes colombianos, alentados por la consagración de los derechos asistenciales en Weimar, a la protección no únicamente de los derechos individuales, sino también de los sociales.

Precisamente, se observa que en la sesión del día 9 de enero de 1936, los Senadores Moisés Prieto y Gerardo Molina, se pronunciaron en favor de la Reforma total de la Constitución exponiendo el primero lo siguiente:

"no comparto con mi amigo el doctor Echandia, el concepto de que la constitución es simplemente el freno a los hombres que ejercitan el Poder Público... ya no se trata solamente de garantizar los abusos (sic) del poder público, ya no se trata de garantizar los derechos del individuo, sino que ha aparecido un concepto nuevo y es el de garantizar los derechos sociales dentro de la Carta Fundamental"40 (Negrillas fuera del texto).

A su vez, desde el punto de vista legal, en octubre de 1936 se establece en Colombia un proyecto relacionado con los derechos sociales, mediante la creación de la caja de seguros sociales dependiente del Ministerio de Industrias, la que cubriría los riesgos de enfermedad, invalidez prematura y maternidad ${ }^{41}$; para este fin, se toman como base sistemáticamente las leyes alemanas, mediante las cuales se "crea una nueva forma de seguro social a través del seguro a supervivientes del trabajador que fallece" 42 .

39 FERNÁNDEZ BOTERO, Eduardo. Las constituciones colombianas comparadas. Editorial Universidad de Antioquia. Medellín. 1964. p. XXVI y ss.

40 TIRADO MEJÍA, Alvaro, et al. Reforma Constitucional de 1936. Op. cit. p. 45.

41 RENGIFO O, Jesús María. La Seguridad Social en Colombia. Op. cit. p. 44.

42 TIRADO MEJÍA, Alvaro, et al. Reforma Constitucional de 1936. Op. cit. p. 24. 
Asimismo, un referente importante para la expedición de las citadas disposiciones, fue la carta weimariana de 1919, a la que se acudió para aclarar las reglamentaciones que en dicha constitución se habían establecido en torno a la protección de los derechos asistenciales, con el fin de aplicarlos en Colombia ${ }^{43}$ tanto a nivel constitucional como legal.

En igual sentido, se observa en el Acta número 27 de la comisión XIV de la sesión del día 26 de febrero de 1936 y cuya presidencia le correspondió al congresista Carlos Pérez, que el representante de apellido Mejía, en una clara posición conservadora -y haciendo alusión al contexto alemán, contraria a la filosofía socialdemócrata promotora de la carta weimariana-, relaciona la "caridad" con la asistencia social de esta manera: "La asistencia social está inspirada en los principios del cristianismo, como un medio más eficaz de caridad que el de la limosna individual" 44 (Negrillas fuera del texto).

Más tarde, en el año de 1963 se desarrolla en Colombia el concepto de asistencia pública directamente relacionado con los servicios de salud, y dirigido a los sectores vulnerables de la sociedad, pero ya no desde el punto de vista "caridad" sino señalado como "derecho" de los ciudadanos. Lo anterior se plasma en el decreto extraordinario No. 3224 de 1963, que indica:

"La asistencia pública como función del Estado, consiste en la ayuda que este debe prestar para procurar el bienestar individual, familiar y colectivo, mediante la prevención de la enfermedad, la promoción y recuperación de la salud de quienes careciendo de medios de subsistencia y de derecho para exigirla de otras personas, estén incapacitados para trabajar" ${ }^{\prime 45}$.

$43 \quad$ Ibíd. p. 29.

44 ANALES DE LA CÁMARA DE REPRESENTANTES. Serie 2. Número 185, marzo 9 de 1936. p. 2501 y ss.

45 PAREDES HERNÁNDEZ, Natalia. Derecho a la salud, su situación en Colombia. Op. Cit. p. 44. Como referencia es importante señalar que en Ecuador en el año de 1967 el derecho a la seguridad social se consagra como el
Con posterioridad, el constituyente de $1991^{46}$ recoge las disposiciones tendientes tanto a la protección de los derechos sociales asistenciales en salud como a la vida ${ }^{47}$, consagradas por el constituyente colombiano del 36 , influenciado por la consagración de los citados derechos en la carta weimariana. Así, el artículo 366 de la Constitución Colombiana del $91^{48}$ establece:

"El bienestar general y el mejoramiento de la calidad de la vida de la población son finalidades sociales del Estado. Será objetivo fundamental de su actividad la solución de las necesidades insatisfechas de salud, de educación, de saneamiento ambiental y de agua potable..."

Asimismo, el artículo 48 de la carta constitucional del $91^{49}$ señala:

más amplio de todos los derechos a la seguridad. Se le define en la constitución ecuatoriana en el inciso 2 del artículo 65 del mencionado año "como el que todos los habitantes tienen "a la protección del Estado contra los riesgos de desocupación, invalidez, enfermedad, vejez y muerte, igual que en caso de maternidad y otras eventualidades que los priven de los medios de subsistencia".

46 Hay que indicar que el constituyente del 91 consagró en el Artículo 1 lo atinente al Estado Social de Derecho y la dignidad humana. En Alemania, la dignidad humana consagrada en la ley fundamental alemana (constitución alemana que rige en la actualidad) igualmente en el artículo 1, es de suma relevancia y exige respeto de las autoridades. Para ampliar este punto véase el caso: GEORGIA, Greeg v. Supreme Court (United States) 428 U.S. 153 (1976), que hace relación a la cadena perpetua y "the dignity of man". Hay que anotar que la constitución norteamericana es de corte procedimental y la alemana se centra más en lo sustantivo. Disponible en: https://litigation-essentials. lexisnexis.com/webcd/app?action=DocumentDispla $\mathrm{y} \&$ crawlid $=1 \&$ doctype $=$ cite \&docid $=63+$ Rev. + Jur. $+\mathrm{U}$ .P.R. $+759 \&$ srctype $=$ smi\&srcid $=3$ B $15 \&$ key $=$ b00e 504 2f507ab2a3b5a92178347c9c9 12/12/2010.

47 Véase: GACETA CONSTITUCIONAL COLOMBIANA N. 83. p. 4, columna 3

48 Disponible en: http://www.secretariasenado.gov.co/ senado/basedoc/cp/constitucion_politica_1991_ pr001.html

49 Disponible en: http://www.secretariasenado.gov.co/ senado/basedoc/cp/constitucion_politica_1991_ pr001.html 
"La Seguridad Sociallo es un servicio público de carácter obligatorio que se prestará bajo la dirección, coordinación y control del Estado, en sujeción a los principios de eficiencia, universalidad $y$ solidaridad, en los términos que establezca la Ley...se garantiza a todos los habitantes el derecho irrenunciable a la Seguridad Social".

Lo anterior, dentro del marco del Estado social de derecho de estirpe weimariana ${ }^{51}$, que ha incidido en la organización sociopolítica de naciones como Colombia, bajo el marco del Estado de bienestar ${ }^{52}$, que surge en Europa como resultado de las demandas sociales como la salud al inicio del siglo XX, y reconocidas por primera vez, si bien es cierto de manera abstracta, en la Constitución Alemana de Weimar.

50 TOLÉ MARTINEZ, Julian. La teoría de la doble dimensión de los derechos fundamentales en Colombia, el estado de cosas inconstitucionales, un ejemplo de su aplicación. Revista Mexicana de Derecho Constitucional. Universidad Nacional Autónoma de México. No. 15. México D.F. En esta época ya existen definiciones concisas sobre por ejemplo la seguridad social como "el servicio público que el Estado presta a los asociados en orden a protegerlos contra las contingencias de enfermedades, accidentes, invalidez, vejez y muerte. Son estas contingencias algunas a las que el común de los ciudadanos no puede atender con sus propios medios a las que el Estado Contemporáneo debe atender directa o indirectamente a través del sistema de seguridad social". Véase igualmente: MIRANDA TALERO, Alfonso. El derecho de la seguridad social. Pontificia Universidad Javeriana. Facultad de Derecho. Bogotá. 1995. p. 19 y el texto de PÉREZ ESCOBAR, Jacobo. Derecho Constitucional Colombiano. Editorial Temis S.A. Bogotá. 1997. p. 343, quien indica que es "el medio que garantiza la subsistencia tanto personal como familiar. Ello significa que el Estado debe cubrir los riesgos que constantemente conspiran contra el individuo y su familia, especialmente por falta de ingresos suficientes para su subsistencia".

51 Aunque se consagran verdaderamente en la ley fundamental alemana.

52 En el Estado de Bienestar se considera que al Estado le corresponde, en su rol de intervencionista, sufragar las necesidades ante todo de los más desfavorecidos, de salud, empleo, y seguridad social en general entre otros. En el Estado de Bienestar la responsabilidad del Estado es mayor en defensa de los intereses y necesidades de los ciudadanos, que deben contar con programas públicos estatales que satisfagan sus necesidades consagradas como "derechos" y no "caridad"
El Estado social de derecho, ligado a los derechos sociales, resumidamente, garantiza "estándares mínimos de salario, alimentación, salud, habitación, educación, asegurados para todos los ciudadanos bajo la idea de derecho ${ }^{53}$ y no simplemente de caridad" ${ }^{\prime 4}$.

Todo este legado normativo que en gran parte se inicia desde la expedición de la Constitución de Weimar en 1919, tuvo una clara incidencia en las disposiciones constitucionales y legales en Colombia. Este escrito no pretende reflexionar sobre las bondades o no de la carta alemana en todos los aspectos, sino hacer una breve referencia a la influencia de la citada Constitución, únicamente ${ }^{55}$ en torno a la consagración de los derechos sociales asistenciales como el de la salud, que se implementaron en Colombia gracias a la constitución alemana ${ }^{56}$, donde se

53 En lo que respecta a los "derechos" es importante estudiar la sentencia de la Suprema Corte de Estados Unidos que se resolvió el 21 de febrero de 1803; se trata del caso Marbury v. Madison, (5 U.S. 137 1803) en el que se argumenta que cuando se tiene un "derecho" se tiene un "poder" facultando al titular para acudir a las autoridades y para hacerlo valer.

54 H.L. WILENSKY, 1975. Citado por la Corte Constitucional en sentencia C-406 de 1992. M.P. Ciro Angarita Barón

55 Es cierto que la Constitución de Weimar tiene muchos contradictores que indican que sus disposiciones tienen un alto grado de abstracción, y que se trata de la consagración de derechos netamente aspiracionales. Igualmente, se argumenta que fue una constitución basada en los compromisos adquiridos mediante el Tratado de Versalles. Véase para ampliar este tema: KIM LANE SCHEPPELE. The Agendas of Comparative Constitutionalism, en law and Courts. Newsletter of the Law and Courts Section of the American Political Science Association. 2003. Disponible en: http://www.law.upenn.edu/cf/faculty/kscheppe/ workingpapers/13Law_Cts5_2003.pdf 12/12/2010

56 En la actualidad, rige la ley fundamental alemana (constitución alemana) que propende porque no se presente ningún tipo de retroceso en lo que a protección de derechos se refiere. Se dice que la ley fundamental alemana fue la respuesta a la Constitución de Weimar de 1919, la cual presentó un catalogo de derechos pero como se dijo anteriormente, aspiracionales y abstractos. La ley Fundamental alemana presenta artículos relevantes como el 79 que indica: 
valoró a la persona como titular de los "derechos $y$ las garantías (y como) elemento integrante de la colectividad" ${ }^{\prime 2}$.

\section{CONCLUSIONES}

La Constitución de Weimar de 1919, es la primera constitución en el mundo que hace referencia a disposiciones de orden social, esto es, consagra normas, así sea a nivel abstracto, que protegen los derechos sociales asistenciales como la seguridad social en salud, las que fueron impulsadas por la socialdemocracia alemana.

Ello hizo que el constituyente colombiano de 1936, bajo el gobierno del presidente Alfonso López Pumarejo, acogiera los nuevos ordenamientos que se estaban presentando en Alemania, tanto a nivel constitucional como legal, encaminados a la protección de los derechos sociales asistenciales como la salud.

En síntesis, la Constitución weimariana de 1919 que consagró los derechos sociales, direccionó las disposiciones tanto constitucionales como legales colombianas alrededor de los derechos sociales, por cuanto los sistemas político y jurídico colombiano, influenciados por las corrientes políticas de izquierda alemanas, sufrieron un ligero viraje ideológico hacia tendencias socialistas; así, los servicios sociales asistenciales en salud, se consagran finalmente desde la órbita de los "derechos" y no como producto de la "caridad".

Los preceptos sociales weimarianos de rango constitucional y las disposiciones legales

"No está permitida ninguna modificación de la presente Ley Fundamental que afecte la organización de la Federación en Länder, o el principio de la participación de los Länder en la legislación, o los principios enunciados en los artículos 1 y 20".

57 FERNÁNDEZ BOTERO, Eduardo. Las constituciones colombianas comparadas. Editorial Universidad de Antioquia. Medellín. 1964. p. 26. Prólogo de Carlos Gustavo Arrieta alemanas en torno a las garantías sociales asistenciales a cargo del Estado, se despliegan con el objeto de proteger progresivamente a la población alemana que clamaba por su derecho a la salud por ejemplo; lo anterior es tomado como referencia o muestra en el contexto colombiano por los constituyentes de 1936 y los legisladores de dicho periodo.

En suma, las normas señaladas en la Constitución de Weimar de 1936, influyeron tanto para la consagración de normas establecidas en la carta magna colombiana y las estructuradas por el legislador nacional, así como en las de otras naciones, las que se inclinaron igualmente a garantizar los principios propios de los derechos sociales asistenciales en seguridad social como la salud, dirigiendo la reorganización estatal a la observancia de estos derechos.

\section{BIBLIOGRAFÍA}

ABREU Y ABREU, Juan Carlos. Derechos Humanos, intereses difusos y medio ambiente: un problema jurídico insoslayable. VI Congreso Iberoamericano de Academias de Derecho. Academia Mexicana de Jurisprudencia y Legislación. 2009. Disponible en: www.acj.org u.v. 24/11/2009

AGUILO REGLA, Joseph. La Constitución como fuente de derecho. Ponencia en el X seminario internacional de Teoría y Filosofía del Derecho. Universidad Nacional de Colombia. Bogotá. 2002. Disponible en: http://www. cervantesvirtual.com/servlet/SirveObras. u.v. 09/11/09

ANALES DE LA CÁMARA DE REPRESENTANTES. Serie 2. Número 185, marzo 9 de 1936.

ARENAS MONSALVE, Gerardo. El derecho colombiano de la seguridad social. Legis Editores S.A. Bogotá. 2009.

BERNAL PULIDO, Carlos. Fundamento, concepto y estructura de los derechos sociales, una 
crítica a ¿Existen derechos sociales? Universidad Externado de Colombia. Bogotá. 2002.

CONSTITUCIÓN NACIONAL DE COLOMBIA DE 1936.

\section{CONSTITUCIÓN POLÍTICA DE COLOM- BIA DE 1991.}

DURAND, Paul. La politica contemporánea de seguridad social. Ministerio de Trabajo y Seguridad Social. Madrid. 1991

FERNÁNDEZ BOTERO, Eduardo. Las constituciones colombianas comparadas. Editorial Universidad de Antioquia. Medellín. 1964

GACETA CONSTITUCIONAL COLOMBIANA N. 83. p. 4, columna 3

GEORGIA, Greeg v. Supreme Court (United States) 428 U.S. 153 (1976), que hace relación a la cadena perpetua y "the dignity of man". Disponible en: https://litigation-essentials. lexisnexis.com/webcd/app?action=Documen tDisplay \& crawlid $=1 \&$ doctype $=$ cite $\&$ docid $=6$ $3+$ Rev. + Jur. + U.P.R. $+759 \&$ srctype $=$ smi\&srcid =3B15\&key $=$ b00e5042f507ab2a3b5a92178347 c9c9 12/12/2010.

H.L. WILENSKY, 1975. Citado por la Corte Constitucional en sentencia C-406 de 1992. M.P. Ciro Angarita Barón

KIM LANE SCHEPPELE. The Agendas of Comparative Constitutionalism, en law and Courts. Newsletter of the Law and Courts Section of the American Political Science Association. 2003. Disponible en:http://www.law.upenn.edu/ cf/faculty/kscheppe/workingpapers/13Law_ Cts5_2003.pdf 12/12/2010

\section{LEY FUNDAMENTAL ALEMANA .}

MOLINA, Gerardo. Las ideas liberales en Colombia. Tomo I. 1848-1914. $8^{a}$ edición. Ediciones Tercer Mundo. Bogotá.

MIRANDA TALERO, Alfonso. El derecho de la seguridad social. Pontificia Universidad Javeriana. Facultad de Derecho. Bogotá. 1995.

PAREDES HERNÁNDEZ, Natalia. Derecho a la salud, su situación en Colombia. Ediciones Antropos Ltda.. Bogotá. 2003.

PÉREZ VILLA, Jorge. Compendio de Derecho Constitucional. Editorial Leyer. Bogotá. 1998.

PÉREZ ESCOBAR, Jacobo. Derecho Constitucional Colombiano. Editorial Temis S.A. Bogotá. 1997.

RENGIFO O, Jesús María. La Seguridad Social en Colombia. Editorial Temis S.A. Bogotá. 1989.

TASCÓN, Tulio Enrique. Historia del Derecho Constitucional Colombiano. Universidad Externado de Colombia. Bogotá. 2005.

TOLÉ MARTINEZ, Julian. La teoría de la doble dimensión de los derechos fundamentales en Colombia, el estado de cosas inconstitucionales, un ejemplo de su aplicación. Revista Mexicana de Derecho Constitucional. Universidad Nacional Autónoma de México. No. 15. México D.F.

TIRADO MEJÍA, Alvaro, et al. Reforma Constitucional de 1936. Colección Pensadores Políticos Colombianos. Cámara de Representantes de Colombia. Bogotá. 1986.

VANOSSI, Jorge Reinaldo. El Estado de Derecho en el Constitucionalismo Social. Editorial EUDEB. Buenos Aires. 1994. 
